\title{
JOHN M. HOBSON E AS ORIGENS CHINESAS DA REVOLUÇÃO INDUSTRIAL INGLESA DO SÉCULO XVIII
}

Leonardo Vinicius Brisola Barbosa ${ }^{1}$

\section{RESUMO}

A Revolução Industrial Inglesa atualmente é vista pela grande maioria dos historiadores e especialistas como um dos processos mais importantes na história do progresso do desenvolvimento técnico e tecnológico humano. Contudo, ao longo do século XX, diversos autores divergiram quanto a suposta originalidade e criatividade desse acontecimento que mudaria o curso da história. Enquanto alguns autores, como Perry Anderson, destacam o pioneirismo e a genialidade dos empreendedores ingleses no desenvolvimento da Revolução Industrial, outros, como Andre Gunder Frank, destacam a importância das inovações oriundas do continente asiático, que na realidade teriam sido assimiladas pela Inglaterra industrial. A partir da análise da obra The Eastern Origins of Western Civilisation, de John M. Hobson, este artigo procura identificar e destacar a influência que inovações tecnológicas originárias da China antiga tiveram sobre a Revolução Industrial Inglesa, uma vez que o autor argumenta que a China Song (960-1279) teria produzido uma primeira revolução industrial em larga escala já no século XI, e muitas dessas inovações teriam sido copiadas e transferidas diretamente para a Inglaterra no século XVIII. PALAVRAS-CHAVE: Revolução Industrial; China antiga; Eurocentrismo; Asiocentrismo.

\section{Introdução}

Ao longo do século XX, diferentes correntes historiográficas se debruçaram exaustivamente sobre os grandes dilemas e questões referentes à Revolução Industrial. Diversos autores debateram e refutaram calorosamente argumentos quanto à sua relevância para o mundo moderno, quais condições foram necessárias para propiciar esse ocorrido e qual o motivo de ela ter ocorrido primeiramente na Inglaterra e não em qualquer outro lugar do mundo. As respostas mais convincentes para essas questões foram formuladas em consonância ou com as ideias marxistas ou com as ideias weberianas. Essas ideias, representantes do "padrão" seguido pela historiografia sobre a Revolução Industrial, apesar de possuírem divergências entre si, partiam todas de um mesmo princípio

1 Mestrando em Humanidades (História) pela Hong Kong University of Science and Technology. E-mail: 1vbb@connect. ust.hk 
básico resultante de seu contexto geográfico e histórico: o Eurocentrismo (HOBSON, 2004, p. 12).

Dentro desses moldes eurocêntricos, as civilizações modernas europeias, como a inglesa durante a Revolução Industrial, eram vistas por grande parte dos historiadores da primeira metade do século $\mathrm{XX}$ através de um triunfalismo europeu, que as enxergava como dotadas de uma inventividade e racionalidade únicas e, assim, justificavam o seu destino iminente ao progresso. Enquanto isso, durante esse mesmo período, grandes e importantes civilizações dos continentes asiático e africano eram consideradas apenas como sociedades imitativas, ignorantes, irracionais e passivas (HOBSON, 2004, p. 8).

Os processos de descolonização na África e na Ásia, derivantes da derrocada do poder das potências imperiais europeias no início da segunda metade do século XX, trouxeram novos questionamentos sobre a consistência do continente europeu como o centro da história do progresso global. A partir dessas tendências, nasce um movimento de reabilitação do Oriente na história mundial, conhecido como "asiocentrismo" ou anti-eurocentrismo. Um dos primeiros autores a popularizar a prática foi Edward W. Said, que, em sua obra Orientalism: Western Conceptions of the Orient, de 1978, critica essa linha de pensamento que enxerga uma hegemonia apriorística do continente europeu sobre todos os povos (SAID, 1978, p. 13-41).

A partir das portas abertas por Said, diversos historiadores resolveram revisitar as questões sobre a RevoluçãoIndustrialnaInglaterra,mas, dessavez,tomarammaioresprecauçõesparanãoseremeurocêntricos, além de tentarem entender quais correlações entre Ásia e Europa permitiram a ocorrência desse processo de desenvolvimento. Essa pesquisa procurará expor algumas das ideias desses revisionistas, com um enfoque especial aos conceitos de Revolução Industrial Chinesa apresentados por um dos mais recentes e mais importantes expoentes dessa tendência, John M. Hobson na obra The Eastern Origins of Western Civilisation.

\section{A Revolução Industrial e os "asiocêntricos"}

Um dos primeiros historiadores a questionar profundamente a questão sobre a Revolução Industrial e o Oriente foi Andre Gunder Frank com sua obra ReORIENT: Global Economy in the Asian Age. Publicada no começo dos anos 90, a obra defende uma história sistêmica do mundo, em que o autor argumenta que foi apenas a partir do século XX que a Ásia passou a ser economicamente inferior a Europa, tanto em produção quanto em produtividade. Para isso, Frank defende uma visão em que, até o fim do século XVII, a Europa estaria muito atrás da Ásia e, por isso, teve que se manter no comércio mundial em um longo período de déficit comercial. Isso apenas foi possível porque países como Portugal e Espanha tiveram a sorte de encontrar grandes quantias de minas de prata nas Américas para manter esse comércio fluindo. Frank entende que a Europa ultrapassou a Ásia economicamente apenas a partir da Revolução 
Industrial, mas se questiona sobre os motivos de ela ter acontecido na Europa, e não na Ásia (FRANK, 1998, p. 8). Segundo sua explicação, a abundância e o baixo preço da mão de obra e os altos preços dos materiais necessários para a industrialização tornavam uma revolução desse teor mais prejudicial do que lucrativa às sociedades orientais, enquanto que para a Europa a ideia era muito mais atrativa.

Um outro importante autor que escreveu sobre o tema foi Kenneth Pomeranz em The Great Divergence: China, Europe, and the Making of the Modern World Economy. Publicada no ano 2000, essa obra, que possui teor mais moderado que a de Frank, argumenta a favor de uma equidade entre os lugares mais desenvolvidos na Europa e na Ásia em expectativa de vida, consumo e comércio, e que a Revolução Industrial ocorreu primeiramente na Europa devido principalmente às diferenças ecológicas, às explorações ultramarinas e à obra da sorte. Assim, ele se opõe a uma gama de autores que diziam haver ocorrido uma gradual "acumulação de forças" que foi aos poucos criando as bases econômicas, tecnológicas, sociais e ideológicas para a industrialização. Pomeranz acredita que a época pré-Revolução Industrial estava cercada de dramáticas limitações ecológicas tanto na Europa quanto na Ásia (POMERANZ, 2000, p. 3-25). De modo a refutar o argumento de que a Revolução Industrial se deu na Europa principalmente devido à superioridade de suas instituições e aos níveis comercial e tecnológico mais avançados, o autor conclui que os fatores principais para esse acontecimento foram a sorte da Inglaterra em possuir reservas de carvão grandes e facilmente alcançáveis, e ao fato do país ter consolidado colônias na América do Norte, o que possibilitou um alívio ecológico para a Europa.

O terceiro historiador a ser apresentado é o chinês Roy Bin Wong, autor de China Transformed: Historical Change and the Limits of European Experience. Em sua obra, Wong argumenta que, até a Revolução Industrial, a Europa e a China apresentavam dinâmicas econômicas parecidas e que essa revolução teria acontecido na Europa pelos mesmos motivos apontados por Pomeranz. No entanto, o autor enfatiza as especificidades da formação dos estados europeus, argumentando que na Europa os estados tinham que se preocupar em competir com seus vizinhos, eram ameaçados constantemente com o perigo de desmembramento territorial e que a nobreza precisava manter seu poder delimitando os poderes da realeza. Enquanto que a China se manteve um império agrário centralizado, sem grandes nobrezas nem grandes rivais desde o século VI com a dinastia Sui, o que diminuiu o incentivo ao desenvolvimento de uma revolução industrial (WONG, 1997, p. 17). 


\section{Hobson e a "Revolução Industrial Chinesa"}

John M. Hobson, a partir da inspiração tirada desses autores, publicou em 2006 a obra revisionista The Eastern Origins of Western Civilisation. Embora possa ser considerado um sucessor mais radicalizado de Andre Gunder Frank, Hobson argumenta em sua obra que, além da Europa ter ultrapassado economicamente a Ásia apenas em 1840, esse desenvolvimento ocidental, foi, na realidade, derivado em grande parte dos avanços técnicos e tecnológicos propiciados pelos próprios países asiáticos. Para o autor, o Ocidente só chegou ao seu progresso material durante a Revolução Industrial graças à assimilação e apropriação das ideias, instituições e tecnologias orientais. Ele afirma que através dos árabes, o Oriente, além de transmitir os conhecimentos gregos há muito esquecidos pelos europeus medievais, também racionalizou diversos conhecimentos e inventos científicos, produzindo uma Renascença e uma Revolução Industrial anterior à europeia, que teriam sido ambas claramente apropriadas pelas cidades italianas e pela Inglaterra.

Em sua obra, Hobson condena as visões consideradas por ele "eurocêntricas" da história do desenvolvimento industrial das sociedades humanas, que veriam os processos ocorridos na Inglaterra do século XVIII como o "primeiro milagre industrial do mundo" e o divisor de águas que mudaria para sempre a história das tecnologias ${ }^{2}$. Para o autor, a China teria passado por um "milagre industrial" de caráter tão importante e grandioso quanto a Revolução Industrial Inglesa, e que, além disso, ele teria acontecido centenas de anos antes do processo britânico. Primeiramente, Hobson aponta para evidências que comprovam que o estado chinês, ainda durante o século VI a.C., já possuía os conhecimentos científicos necessários para produzir objetos feitos de ferro, e que durante os anos 800 e 1100, sob o império da próspera dinastia Song, teria ocorrido um crescimento gigantesco na produção de ferro, isso fez a produção chinesa anual saltar de 13,500 toneladas em 806 para 125,000 toneladas em 1075, enquanto a Inglaterra atingiu uma produção de apenas 76,000 toneladas anuais só em 1788, setecentos anos mais tarde (HOBSON, 2004, p. 51).

Além disso, apesar de não os nomear, Hobson refuta outros historiadores que propunham que a produção chinesa de ferro era apenas utilizada para a produção de armamentos e decoração, argumentando que os baixíssimos preços do ferro, quando comparados com os preços do arroz, permitiram que houvesse uma verdadeira "revolução" na produção de muitos artigos do dia a dia e da sociedade Song em geral, como facas, machadinhas, formões, brocas, martelos, marretas, arados, pás, eixos de carrinho de mão, rodas, ferraduras, tachos, panelas, chaleiras, sinos, correntes, portões, torres de vigia, pontes, molduras e tipos de impressão, que só passariam a ser vistos pela humanidade novamente na Inglaterra industrial (HOBSON,

2 Hobson menciona principalmente Perry Anderson, Lineages of the Absolutist State (London: Verso, 1979); Alan K. Smith, Creating a World Economy (Boulder: Westview Press, 1991); e David S. Landes, The Wealth and Poverty of Nations (London: Little, Brown, 1998). 
2004, p. 52). O autor ainda complementa sua argumentação demonstrando a prematuridade da fundição do aço na China (já no século II AEC.), a substituição do combustível feito de coca pelo uso do carvão, e as imensas inovações tecnológicas presentes na manufatura têxtil da seda, todas características marcantes do que pode ser considerado uma revolução industrial (HOBSON, 2004, p. 53).

Outra "falácia eurocêntrica" que Hobson procura superar em sua obra é a da noção de que, embora se considere que a dinastia Song realmente tenha proporcionado uma revolução industrial ainda no século XI, esse processo teria se constituído em nada mais do que uma "revolução abortiva", com um crescimento extremamente limitado e seguido por estagnação e isolacionismo comercial que teriam sido causados majoritariamente pela proibição do comércio exterior promovido pela dinastia Ming em 1434 (ANDERSON, 1979, p. 541-546). Hobson argumenta que a expedição dessa ordem imperial que proibiu o comércio foi mal interpretada pelos historiadores eurocêntricos e que o espírito mercantil e o comércio continuaram a fluir normalmente na China Ming. Como evidências, ele primeiramente aponta para o fato de que se mantinha no império uma política oficial de valorização dos valores confucionistas, que acabaram privilegiando uma hierarquia oficial que posicionava os mercadores nos níveis mais baixos do estrato social, portanto, a lei de 1434 servia, na visão de Hobson, para materializar simbolicamente uma ideia anti-mercantil que compunha a identidade e a legitimidade do estado confucionista (HOBSON, 2004, p. 62). Contudo, ele afirma que os governantes Ming, por saberem do valor intrínseco da participação do estado no mercado global, mantiveram propositalmente um sistema de tributos e "vassalagens" que serviam como uma porta de entrada para o comércio chinês, disfarçados de presentes e tributações oferecidos ao imperador. Em segundo lugar, o autor apresenta sólidas evidências de que muitos mercadores chineses conseguiram manter seu comércio extremamente lucrativo ao burlar e ignorar as novas regras e praticar pirataria tanto com os mercadores europeus de Portugal, dos Países Baixos e da Espanha, quanto com o mercado asiático do Japão, da Coreia, e do Sudeste Asiático, tudo sob os olhos propositalmente desatentos das autoridades (HOBSON, 2004, p. 64).

Baseando-se nesse conjunto de argumentos, Hobson propõe não apenas o reconhecimento do que ele chama de uma "Revolução Industrial Chinesa", mas também deixa implícito que essa revolução, diferentemente do que é habitualmente argumentado por historiadores eurocêntricos, teve uma importância para a história global tão grande quanto, e talvez até maior do que, a Revolução Industrial ocorrida na Inglaterra do século XVIII, uma vez que foi capaz de manter um legado forte o suficiente para influenciar em grande parte o desenvolvimento industrial das próprias sociedades europeias seis séculos mais tarde. 


\section{As origens chinesas da Revolução Industrial Inglesa}

As correntes históricas mais comumente difundidas até o início do século XXI geralmente encaravam a Revolução Industrial como um processo que aconteceu primeiramente na Inglaterra a partir da segunda metade do século XVIII, devido em grande parte a motivos endógenos e originais próprios das condições materiais e intelectuais desse contexto. Dentro desse conjunto de autores consolidados, por um lado temos historiadores como Phyllis Deane, que já no título de sua obra The First Industrial Revolution (1965), deixa explícito seu posicionamento quanto ao pioneirismo industrial inglês; por outro lado também temos obras marxistas como a de Perry Anderson, que em Linhagens do Estado Absolutista (1979), afirma ter sido a Revolução Industrial "uma gigantesca e espontânea combustão das forças de produção, única em seu poder e universal em seu alcance" (ANDERSON, 1979, p. 419-420). O que a maioria dessas tradições, mesmo que distintas em suas interpretações e pensamentos históricos, possui em comum quanto à análise da Revolução Industrial é que elas acreditam que esse processo consistiu um movimento inédito alcançado por um individualismo e uma inventividade única dos anglo-saxões da época (HOBSON, 2004, p. 191). É exatamente contra esses preceitos eurocêntricos que Hobson irá se contrapor duramente em sua exposição.

Primeiramente, Hobson argumenta que o continente europeu não era excepcional, rejeitando a ideia de que seus governantes e intelectuais possuíam uma espécie de inventividade única, representada pela desenvolvimento do Iluminismo. Em vez de criar teorias sociológicas e econômicas pensando exclusivamente no contexto europeu, as elites intelectuais do pensamento iluminista teriam, segundo Hobson, se especializado em assimilar e refinar as ideias e as teorias econômicas pertencentes à terra da primeira revolução industrial, isto é, a China antiga. Hobson usa como evidência a grande admiração que pensadores iluministas ocidentais como Voltaire, Adam Smith, Leibniz e Hume tinham pelos sistemas político e econômico do grande império oriental, que teria como base uma suposta racionalidade intrínseca aopensamentotradicional chinês wú wéi (無為, não-ação), que teria sido atémesmo, mais tarde, assimilado pelo importante filósofo francês François Quesnay na forma de laissez-faire (HOBSON, 2004, p. 197).

Além de observar as origens chinesas do Iluminismo, Hobson também aponta para as origens chinesas da "revolução agrícola inglesa", um conjunto de inovações tecnológicas no campo que permitiram o aumento da produção alimentícia, e que é tradicionalmente considerada como um dos precursores cruciais para a Revolução Industrial. Ele aponta para a real natureza de diversas ditas “inovações tecnológicas” europeias como puras assimilações de técnicas e aparelhos há muitos séculos já utilizados pelas civilizações chinesas, como o arado de Rotherham, alegadamente adaptado de uma

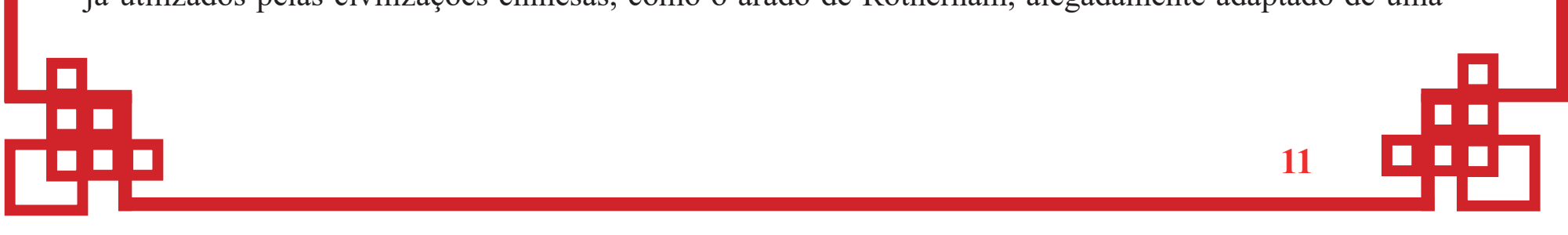


invenção holandesa do século XVII, mas que já era usada na China dois milênios antes (HOBSON, 2004, p. 202); a peneira giratória, que foi introduzida na Europa por jesuítas franceses em 1720, mas já utilizada desde o século II AEC pelos chineses (HOBSON, 2004, p. 203); as semeadeiras e a criação de cavalos-capinadores, ambas descobertas pelo ingleses apenas no século XVIII, mas que já estavam em voga desde o terceiro século antes da era comum na China (HOBSON, 2004, p. 205); e principalmente as revolucionárias rotações de culturas, praticadas pelos britânicos desde o século XVIII, mas que já era conhecida pelos chineses desde o século VI (HOBSON, 2004, p. 206).

Ademais, para Hobson, a influência das tecnologias chinesas na Inglaterra não parou simplesmente na revoluçãoagrícola,mastambémpenetrouprofundamentenasprópriasinovaçõesqueficariammundialmente conhecidas como "descobertas" próprias do pioneirismo dos britânicos. O autor argumenta que muitas das novidades do século XVIII, como o uso extensivo de carvão como combustível, a produção de ferro e aço, a produção em larga escala de tecidos (no caso, da seda) e o próprio motor a vapor foram inventados e praticados na China entre 2300 e 700 anos antes de serem introduzidos na Inglaterra (HOBSON, 2004, p. 207-217).

A partir de todas as críticas dirigidas à versão eurocêntrica da história da industrialização na Inglaterra, Hobson procura deixar claro em sua obra que, apesar da Revolução Industrial Chinesa haver tido uma importância vital para o desenrolar da Revolução Industrial Inglesa, não se deve menosprezar a importância da segunda como a propagadora das ideias da primeira para o resto do mundo ocidental, especialmente para os continentes europeu e americano. Em seu ponto de vista, a sociedade inglesa do final do período moderno não merece o título de "inventiva", como é usualmente pregado por estudiosos eurocêntricos, mas sim, o título de uma eficiente “assimilacionista", que, partindo das vantagens de um "late developer", isto é, as vantagens de um país tecnologicamente atrasado que conseguiu se desenvolver através da aprendizagem de tecnologias mais avançadas vizinhas, conseguiu, com o mérito da assimilação, produzir sua própria revolução.

\section{Considerações finais}

Uma das explicações mais bem aceitas sobre o porquê de a Revolução Industrial ter ocorrido "primeiro" na Inglaterra nos é fornecida pelo historiador marxista Eric Hobsbawm em sua obra A Era das Revoluções: um ambiente de absolutismo fraco, o sucesso do projeto imperialista britânico, as bem-sucedidas guerras contra a Holanda, a ampla oferta de mão de obra gerada pelos cercamentos, uma classe média burguesa portadora de um capital mediano e um mercado externo substancialmente ilimitado (HOBSBAWM, 1967, p. 54-89). Contrastando essa visão com a de Hobson, é impossível 
BARBOSA, L. John M. Hobson e as origens chinesas da Revolução Industrial do século XVIII, pp. 06-13.

não notarmos a falta de dois itens primordiais: o assimilacionismo de propriedades intelectuais chinesas e o extremo atraso técnico-tecnológico de mais de sete séculos presente na Inglaterra.

Apesar de Hobson mencionar muitas vezes "autores eurocêntricos", que pela falta de referências, não raramente acabam se parecendo mais com "autores espantalhos", é incontestável o fato de que ele está dialogando com uma historiografia que realmente existe e domina ainda hoje grande parte do conhecimento das ciências humanas. Com a ressalva de certos exageros como apontar as origens do Iluminismo para tradições confucionistas antigas, Hobson se mostra coerente ao desafiar o senso comum de uma historiografia que, acostumada a enxergar a Europa como superior à Ásia devido às suas “instituições superiores", lida com a Revolução Industrial de forma teleológica, assumindo que as civilizações da Europa sempre foram o centro do desenvolvimento humano no mundo e que assim seguirão sendo.

Por fim, ao aplicar e atualizar as ideias de grandes autores revisionistas como Said, Frank, Wong e Pomeranz, Hobson ajuda a manter esse importante debate vivo, e The Eastern Origins of Western Civilisation, apesar de ser exageradamente radical em alguns momentos, cumpre seu objetivo principal de explicar a história, nesse caso a Revolução Industrial, a partir de um ponto de vista mais globalista e, consequentemente, menos eurocêntrico.

\section{Referências bibliográficas}

ANDERSON, Perry. Lineages of the Absolutist State. London: Verso, 1979.

DEANE, Phyllis Deane. The First Industrial Revolution. Cambridge: Cambridge University Press, 1965. FRANK, Andre Gunder. ReOrient: Global Economy in the Asian Age. Berkeley: University of California Press, 1998.

HOBSBAWM, Eric. A Era das Revoluções 1789-1848. São Paulo: Paz e Terra, 1967.

HOBSON, John M. The Eastern Origins of Western Civilisation. Cambridge: Cambridge University Press, 2004

POMERANZ, Kenneth. The Great Divergence: China, Europe, and the Making of the Modern World Economy. Princeton: Princeton University Press, 2000.

SAID, Edward W. Orientalism: Western Conceptions of the Orient. New York: Pantheon Books, 1978.

WONG, Roy Bin. China Transformed: Historical Change and the Limits of European Experience. Cornell: Cornell University Press, 1997. 